\title{
Association in Long-Evans Hooded Rats of Red Cell 2,3-Diphosphoglycerate Levels with Hemoglobin Types
}

\author{
G. Brewer, ${ }^{1}$ J. Gilman, ${ }^{1}$ N. Noble, ${ }^{1}$ and V. Crews ${ }^{1}$
}

Received 28 July 1977-Final 21 Dec. 1977

Two sublines of commercially available Long-Evans hooded rats have been developed by genetic selection. These sublines have widely differing levels of erythrocyte 2,3-diphosphoglycerate (DPG) due to different alleles at a single genetic locus. In the present work, it is shown that rats from the commercial population are also polymorphic at a hemoglobin locus, probably involving two alleles of the ${ }^{I I I} \beta$-globin chain locus. Particular hemoglobin types have been found to be strongly associated with certain DPG types, not only in the high-DPG and low-DPG lines but also in the commercial population. Two explanations for this association are considered. One is a single-locus hypothesis, with hemoglobin allelic variation causing DPG variation, and the other is a two-locus hypothesis, with marked linkage disequilibrium.

KEY WORDS: Long-Evans hooded rats; erythrocyte 2,3-diphosphoglycerate; hemoglobin.

\section{INTRODUCTION}

One of the important variables determining relative oxygenation of tissues, along with cardiac output, pulmonary ventilation, and hemoglobin levels, is red cell oxygen affinity. The oxygen affinity of the erythrocytes of most mammals, including man and the rat, is finely tuned by the levels of 2,3-diphosphoglycerate (DPG) (Benesch and Benesch, 1967; Chanutin and Curnish, 1967; Brewer and Eaton, 1971; Brewer, 1974). DPG is a product of red cell glycolysis; thus a biochemical and functional relationship exists

This work was supported by a Michigan Heart Association Grant, by the Meyers Foundation, and by NIH Training Grant (5 T01-GM-0071).

${ }^{1}$ Departments of Human Genetics and Medicine, University of Michigan, Ann Arbor, Michigan 48109. 
between red cell carbohydrate metabolism and the hemoglobin carried within the cell.

We have previously described genetic variation in DPG levels in LongEvans hooded rats obtained from the random-bred population of Simonsen Laboratories, Gilroy, California (Noble and Brewer, 1972). True-breeding high-DPG and low-DPG lines were developed by genetic selection. The operation of single major gene, with two alleles, was subsequently shown to account for the differences in DPG levels between these lines (Noble and Brewer, 1977). In the present article, we have named the high-DPG allele $D$ and the low-DPG allele $d$.

While studying the genetic polymorphism for DPG level in the randombred Long-Evans hooded rats and the high-DPG and low-DPG derived lines, it was noted that various rats differed in the starch gel electrophoretic patterns of their hemoglobins. This variation appears to correspond precisely to that reported by French and Roberts (1965), by Brdicka (1967), and by Marinkovic et al. (1967), and further described by Martinovic et al. (1970) and Travnicek et al. (1971). The genetic studies of French and Roberts (1965) and Martinovic et al. (1970) indicate that this variation is genetically determined and is due to a single-locus, two-allele system. In conformity with the nomenclature of earlier workers (Brdicka, 1967; Travnicek et al., 1971; French et al., 1971), we will refer to the two alleles of this hemoglobin polymorphism as $a$ and $b$.

In this article, we report the results of a study of the relationship between the $D, d$ polymorphism for DPG level and the $a, b$ hemoglobin polymorphism in hooded rats. These data show a clear association of the $D$ allele for high-DPG level with the $b$ hemoglobin allele in Long-Evans hooded rats, and of the $d$ low-DPG allele with $a$ hemoglobin. We also report a survey of DPG levels and hemoglobin types in a large number of inbred strains of rats. Our results support the hypothesis that the genes in hooded rats controlling DPG level and the genes for hemoglobin type are distinct but closely linked, and are in linkage disequilibrium, although we cannot formally exclude the possibility that the hemoglobin locus itself may be responsible for the variation in DPG level. Regardless of the explanation for the association, its existence is interesting because of the close functional relationship between the hemoglobin and DPG molecules.

\section{METHODS}

Blood was obtained from rats by intracardiac puncture under ether anesthesia, at a standard age of 6 weeks. The levels of red cell DPG were determined by a modification of the method of Keitt (1971) on trichloroacetic acid extracts, and are expressed as $\mu$ moles per gram of hemoglobin. 
Hemoglobin electrophoretic phenotypes were determined using starch gel electrophoresis at $p \mathrm{H} 8.6$, with $0.045 \mathrm{M}$ tris/ $0.025 \mathrm{M}$ boric acid/0.001 $\mathrm{M}$ EDTA (Smithies, 1965). In order to avoid the problem of rat hemoglobin precipitation, care was taken to keep the hemoglobin solutions alkaline.

The control Long-Evans hooded rats were obtained from Simonsen Laboratories, Gilroy, California. The high-DPG and low-DPG Long-Evans hooded rats were from the lines we have developed by genetic selection as previously described (Noble and Brewer, 1972, 1977). The inbred rat lines were kindly supplied by Dr. Carl Hansen at NIH.

\section{RESULTS}

\section{Hemoglobin Types}

Figure 1 shows electrophoretic patterns of the three hemoglobin phenotypes we have found in rats, in agreement with Brdicka (1967), Marinkovic et al.

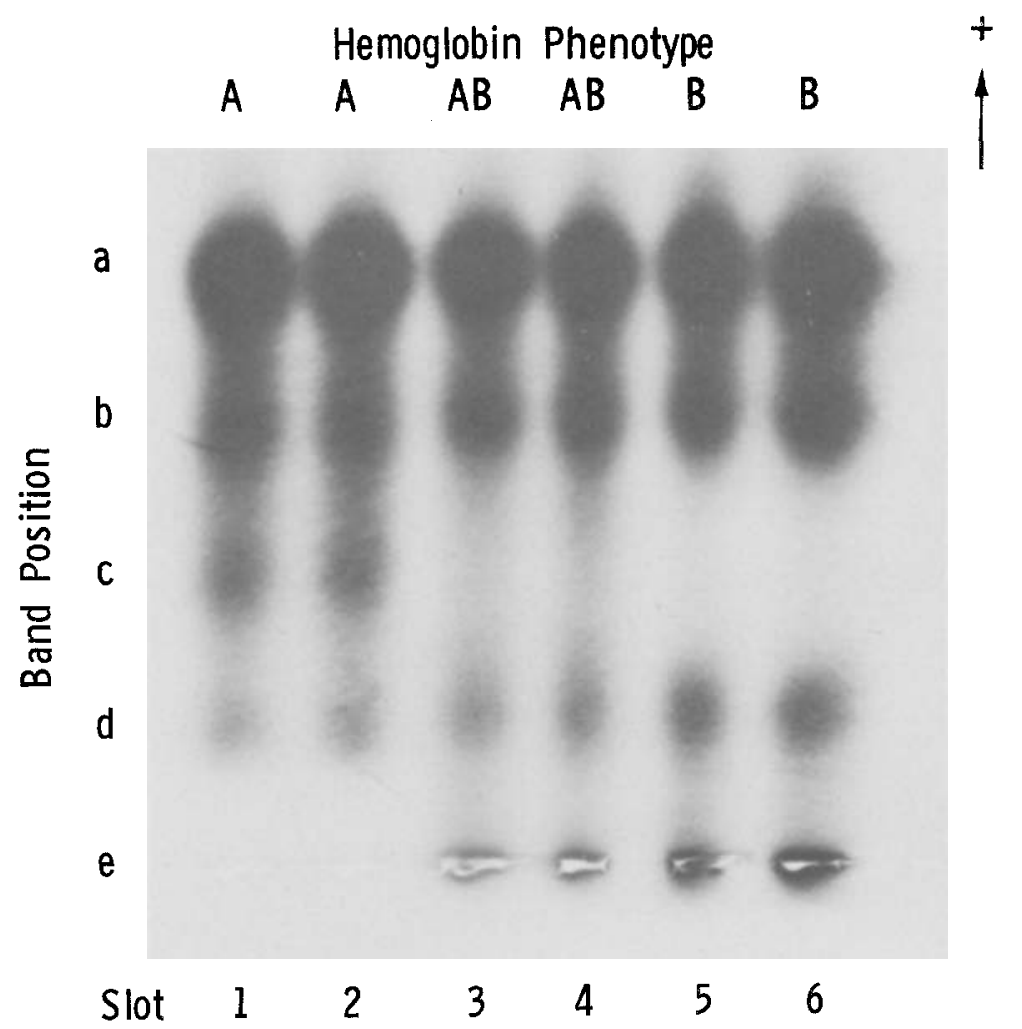

Fig. 1. The three homoglobin phenotypes as shown by starch gel electrophoresis. 
(1967), Martinovic et al. (1970), and Travnicek et al. (1977). Genetic studies, to be discussed shortly, indicate that the pattern in slots 1 and 2 is one homozygote type, which is phenotype $A$, slots 5 and 6 contain a second homozygote type called $\mathrm{B}$, and the heterozygote pattern $\mathrm{AB}$ is in slots 3 and 4 . This nomenclature is in keeping with that of Brdicka (1967) and Travnicek et al. (1971). These three patterns correspond to types I, III and II, respectively, of Marinkovic et al. (1967) and Martinovic et al. (1970).

\section{Genetic and Population Studies}

As we initiated our study of the hemoglobin polymorphism in these hooded rats, it soon became apparent that the hemoglobin phenotype B was associated with the DPG genotype $D D$ and that hemoglobin type A was associated with DPG genotype $d d$. We then initiated a genetic study, crossing various types of animals, and making observations on both hemoglobin and DPG phenotypes.

In Table I are shown the results of three types of mating of known DPG homozygotes from the high-DPG and low-DPG lines. Table I will also serve to define operationally the range of DPG levels expected from the $D D, d d$, and $D d$ genotypes. Cross I (Table I) involved animals of the high-DPG line only, all known to be $D D$, and invariably found to be homozygous for the $b$ hemoglobin allele. Thus cross I was $D D b b \times D D b b$ and all 66 progeny from nine matings had hemoglobin genotype $b b$, and DPG concentrations ranging from 27.05 to $34.69 \mu$ moles. Cross II (Table I) involved only animals of the low-DPG line, all known to be $d d$, and invariably found to be homozygous for the $a$ hemoglobin allele. Thus cross II was $d d a a \times d d a a$ and all 90 progeny

Table I

\begin{tabular}{|c|c|c|c|c|c|c|c|c|c|c|c|c|}
\hline \multirow[b]{2}{*}{ Cross } & \multicolumn{2}{|c|}{ Phenotypes } & \multicolumn{3}{|c|}{$\begin{array}{l}\text { Proposed } \\
\text { genotypes }\end{array}$} & \multirow{2}{*}{$\begin{array}{c}\text { Number } \\
\text { of } \\
\text { matings }\end{array}$} & \multirow{2}{*}{$\begin{array}{l}\text { Total } \\
\text { number } \\
\text { of } \\
\text { progeny }\end{array}$} & \multicolumn{2}{|c|}{$\begin{array}{c}\text { Phenotypes } \\
\text { DPG }\end{array}$} & \multirow[b]{2}{*}{$\mathrm{Hb}$} & \multicolumn{2}{|c|}{$\begin{array}{l}\text { Proposed } \\
\text { genotypes }\end{array}$} \\
\hline & DPG & $\mathrm{Hb}$ & DPG & & $\mathrm{Hb}$ & & & Mean & Range & & DPG & $\mathrm{Hb}$ \\
\hline \multirow[t]{2}{*}{ I } & High & B & $D D$ & & $b b$ & 9 & 66 & 30.69 & $27.05-34.69$ & All B & All $D D$ & All $b b$ \\
\hline & High & B & & $x$ & $b b$ & & & & & & & \\
\hline \multirow[t]{2}{*}{ II } & Low & A & $d d$ & & $a a$ & 14 & 90 & 21.52 & $18.52-23.83$ & All A & All $d d$ & All $a a$ \\
\hline & Low & A & $d d$ & $\times$ & $a a$ & & & & & & & \\
\hline \multirow[t]{3}{*}{ III } & High & B & $D D$ & & $b b$ & 6 & 40 & 28.79 & $25.8-30.97$ & All AB & All $D d$ & All $a b$ \\
\hline & & & & $x$ & & & $\left(F_{1}\right)$ & & & & & \\
\hline & Low & A & $d d$ & & $a a$ & & & & & & & \\
\hline
\end{tabular}


from 14 matings had hemoglobin genotype $a a$ and DPG levels ranging from 18.52 to $23.83 \mu$ moles. Cross III (Table I) was an intercross between $D D b b$ and $d d a a$, and the $40 \mathrm{~F}_{1}$ progeny from six matings all had hemoglobin genotype $a b$ and DPG levels ranging from 25.8 to 30.97 moles. The range of DPG levels in the heterozygote class is much closer to that of $D D$ than that of $d d$ as previously reported by Noble and Brewer (1977).

These data from Table I may be used to define operationally the DPG levels expected from genotypes $D D, D d$, and $d d$, which definition will be used to characterize the DPG levels in the $\mathrm{F}_{2}$ progeny resulting from the cross $D d$ $a b \times D d a b$. This latter cross was performed in order to try to detect recombination between the DPG and hemoglobin loci, and results are given in Table II. Since the $d d$ homozygote has a range of DPG level which is clearly differentiated from that for $D d$ or $D D$, the DPG range 18.52-23.83 $\mu$ moles defines the expected DPG phenotype of $d d$ animals. The "gap range" is that between $d d$ and $D d$ in the above study-23.83-25.80 $\mu$ moles. The "heterozygote $(D d)$ only range" is defined as $25.80-27.05 \mu$ moles, the " $D d$ and $D D$ overlap range" is $27.05-30.97$, and the "high homozygote $(D D)$ only range" is $30.97-34.69 \mu$ moles.

Nine crosses of the $F_{1}$ heterozygotes of Table I produced $70 \mathrm{~F}_{2}$ progeny, and the hemoglobin and DPG data on these $F_{2}$ animals are summarized in Table II. The expectation for hemoglobin types, assuming a one-locus, twoallele system, is $1: 2: 1$ for $\mathrm{A}, \mathrm{AB}, \mathrm{B}$ types, respectively. For 70 progeny the expectation would be $17.5,35$, and 17.5 animals, which is not significantly different than the 13,37 , and 20 distribution observed by the $\chi^{2}$ test.

The DPG classification of the $\mathrm{F}_{2}$ animals in Table II, based on the data from Table I, shows a clear association between hemoglobin phenotype and DPG levels. Ten of the 13 hemoglobin A animals had DPG levels in the $d d$ range; 16 of 20 hemoglobin $B$ animals had DPG levels within the $D D$ range; 32 of 37 hemoglobin AB animals had DPG levels within the $D d$ range. Next we will briefly discuss the possible exceptions to the DPG hemoglobin types association in the $F_{2}$ of Table II to look for evidence of possible genetic recombination.

The $13 \mathrm{~F}_{2}$ animals of hemoglobin A type showed ten in the $d d$ DPG range, two in the gap range between the $d d$ and $D d$ ranges, and one in the $D d$ range (Table II). The two animals in the gap range had DPG levels of 25.66 and 25.75 , were from the same pedigree, and were mated with each other. The four progeny from this mating all had DPG levels quite close to those of their parents, and were not indicative of a recombinant event having occurred. The likely explanation of the somewhat high values in these two $F_{2}$ animals in the gap range is the presence of other genetic modifiers in this family line, tending to make their values range somewhat high. It should be kept in mind that the variance of DPG values in the $F_{2}$ of the intercrosses is expected to be 

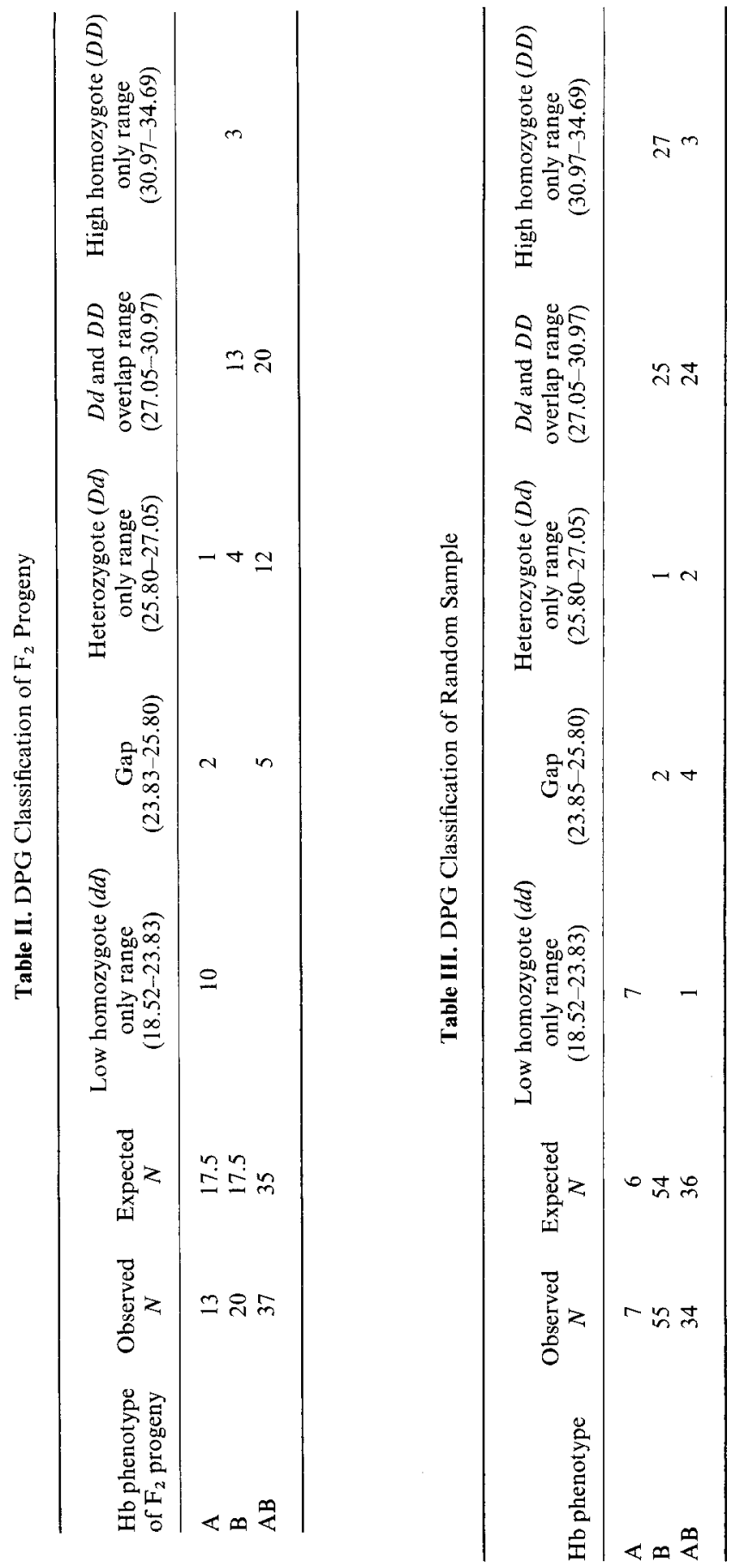
somewhat higher than that in the baselines. This is because the baselines are somewhat inbred (estimated $F$ of 0.3 at generation 11), which tends to reduce the variance. Thus it is not too surprising that some of the values of the $F_{2}$ animals exceed the ranges of the original lines.

The one animal of A hemoglobin type with a DPG level of 26.6 in the $D d$ range is more interesting. This animal was mated with a $d d$ animal. Of the seven progeny (all of A hemoglobin type), two support the possibility of a recombinant event having occurred in the $F_{2}$ parent, with DPG levels of 28.3 and 30.2. The other five progeny had DPG values in the $d d$ or gap range. Work with this family line is continuing. At present, these results are compatible with one recombination in the hemoglobin $\mathrm{A}_{2}$ progeny.

The $20 \mathrm{~F}_{2}$ animals of $\mathrm{B}$ hemoglobin type of Table II showed four animals below the $D D$ homozygote range. The values were $26.3,26.8,26.1$, and 25.9, none of which is very far below the $D D$ homozygote range. The first two animals, which were from the same pedigree, were mated with each other. All eight progeny had DPG values in the typical $D D$ homozygote range. The third animal was also mated with the first animal, and the six progeny had DPG values in the typical $D D$ homozygote range. The fourth animal was mated to an AB heterozygote (DPG level 25.9), and all seven progeny had DPG values in the $D d$ or $D d$ range, as expected. Thus none of the progeny tests of these four animals in indicative of a recombinant event. The likely explanation for the somewhat low DPG values in these four animals of the $b b$ genotype is the presence of other genetic modifiers, as explained above.

The $37 \mathrm{~F}_{2}$ animals of $a b$ hemoglobin genotype of Table II showed five animals in the DPG gap range, a little below the expected level for $D d$ heterozygotes. The values were $25.36,25.45,25.74,23.87$, and 25.57 . The third animal in this group was mated to an $a b D d$ animal. Seven progeny resulted, and of the three $\mathrm{AB}$ progeny none showed low values. We were unable to mate the fourth animal, which had the best possibility of being a recombinant, because it died. Thus we have no good evidence yet of recombination in the $F_{2}$ progeny which were $a b$ hemoglobin genotype. The likely explanation for the somewhat low DPG values in most of the five exceptional animals of the hemoglobin $\mathrm{AB}$ type is the presence of other genetic modifiers.

We next did a survey of a control sample of 96 Long-Evans rats purchased from Simonsen Laboratories. Table III summarizes the results of the hemoglobin and DPG measurements. The distribution of observed hemoglobin phenotypes fits the expected Hardy-Weinberg values quite well (Table III), under the assumption of a single-locus, two-allele system. The allele frequency for $a$ in this sample was 0.25 . A clear association between DPG levels and hemoglobin types is also seen in this sample. There are no exceptions in the A hemoglobin type, three possible exceptions out of 55 in the B hemoglobin type, and five possible exceptions out of 34 in the $A B$ hemoglobin 
type. We assume that many of these exceptions are not truly in the opposite linkage phase, but none has been progeny-tested.

\section{Inbred Rat Line Study}

Finally, we surveyed a series of inbred rat lines obtained from Dr. Hansen at the National Institutes of Health. Table IV summarizes these data. Hemoglobin variation corresponding precisely to that present in the hooded population is also seen between these rat lines. Thirteen of the lines had hemoglobin patterns identical to that of the hooded homozygous a patterns identical to that of the homozygous $b b$ type. Among the 13 hemoglobin A type lines, there was no association with DPG. Four of the lines were

Table IV

\begin{tabular}{|c|c|c|c|c|c|}
\hline \multirow[b]{2}{*}{ Strain } & & \multicolumn{2}{|c|}{ DPG } & \multicolumn{2}{|c|}{ Hb type } \\
\hline & & Level & Type & A & B \\
\hline SHRSP $/ \mathrm{A}_{3} \mathrm{~N}$ & 1 & 26.56 & $\operatorname{Int}^{a}$ & $\mathrm{X}$ & \\
\hline $\mathrm{BN} / \mathrm{SSN}$ & 2 & 27.55 & High & $\mathrm{X}$ & \\
\hline SHR/N & 3 & 27.21 & High & $\mathrm{X}$ & \\
\hline $\mathrm{WK}_{\mathrm{y}} / \mathrm{N}$ & 4 & 29.81 & High & $\mathrm{X}$ & \\
\hline $\mathrm{F}_{344} / \mathrm{N}$ & 5 & 26.84 & Int & $\mathrm{X}$ & \\
\hline $\mathrm{CAS} / \mathrm{N}$ & 6 & 20.82 & Low & $\mathrm{X}$ & \\
\hline $\mathrm{LOU} / \mathrm{Mn}$ & 7 & 21.14 & Low & $\mathrm{X}$ & \\
\hline $\mathrm{OM} / \mathbf{N}$ & 8 & 24.00 & Low & $\mathrm{X}$ & \\
\hline $\mathrm{LA} / \mathrm{N}$ & 9 & 26.37 & Int & $\mathrm{X}$ & \\
\hline PETH/N & 10 & 28.78 & High & & $\mathrm{X}$ \\
\hline $\mathrm{BUF} / \mathrm{N}$ & 11 & 25.33 & Int & & $\mathrm{X}$ \\
\hline $\mathrm{MNR} / \mathrm{N}$ & 12 & 29.03 & High & & $\mathrm{X}$ \\
\hline $\mathrm{WN} / \mathrm{N}$ & 13 & 22.26 & Low & $\mathrm{X}$ & \\
\hline $\mathrm{AC} 1 / \mathrm{N}$ & 14 & 29.85 & High & & $\mathrm{X}$ \\
\hline LEW/SSn & 15 & 30.92 & High & & $\mathrm{X}$ \\
\hline WFU/CRN & 16 & 31.38 & High & $\mathrm{X}$ & \\
\hline $\mathrm{CAR} / \mathrm{N}$ & 17 & 23.65 & Low & & $\mathrm{X}$ \\
\hline $\mathrm{M} 520 / \mathrm{N}$ & 18 & 26.49 & Int & $\mathrm{X}$ & \\
\hline $\mathrm{MR} / \mathrm{N}$ & 19 & 30.09 & High & & $\mathrm{X}$ \\
\hline $\mathrm{ALB} / \mathrm{N}$ & 20 & 23.85 & Low & $\mathrm{X}$ & \\
\hline $\mathrm{NSD} / \mathrm{N}$ & 21 & 31.62 & High & & $\mathrm{X}$ \\
\hline RHA/N & 22 & 32.17 & High & & $\mathrm{X}$ \\
\hline Totals & & $\begin{array}{r}\mathrm{Hb} 4 \mathrm{hig} \\
4 \mathrm{int} \\
5 \mathrm{lor}\end{array}$ & & & \\
\hline
\end{tabular}

a Animals with levels up to 25.0 were called "low," with levels above 27.05 were called "high," and with levels between these values were called "intermediate" (int). 
high DPG, four were low, and four were intermediate. Among the nine hemoglobin B type lines, there was a trend toward the association seen in the hooded, with seven high DPG, one low, and one intermediate.

\section{DISCUSSION}

This article demonstrates the presence of a hemoglobin polymorphism in the Long-Evans hooded rat population of Simonsen Laboratories. This polymorphism, appears to be similar to those reported in other population of rats. The data of the genetic and population study on hooded rats that we report here (Tables I, II, and III) are consistent with the hypothesis that this hemoglobin polymorphism is determined by two alleles at a single locus. The starch gel electrophoretic patterns of the three phenotypes correspond precisely to those earlier reported by French and Roberts (1965), Brdicka (1967), Marinkovic et al. (1967), Martinovic et al. (1970), and Travnicek et al. (1971). The genetic studies of French and Roberts (1965) and Martinovic et al. (1970) also led them to conclude that the variation was determined by a single-locus, twoallele system. In conformity with the nomenclature of Brdicka (1967) and Travnicek et al. (1971), we have referred to the two alleles of this hemoglobin polymorphism, as $a$ and $b$. The $\mathrm{A}, \mathrm{AB}$, and $\mathrm{B}$ hemoglobin electrophoretic patterns correspond to types I, II, and III in the nomenclature of Marinkovic et al. (1967) and Martinovic et al. (1970). Variation in hemoglobin of this type among inbred rat strains is also extensive, as can be seen from Table IV.

The components of hemoglobin involved in this polymorphism are the slower-migrating components labeled c, d, and e in Fig. 1, which comprise about $20 \%$ of the total hemoglobin in adult rats (Travnicek and Sulc, 1967; Garrick et al., 1975). The faster-migrating major components have been monomorphic in all our studies. Rat hemoglobins appear to be composed of five globin chains, two of $\alpha$ type, ${ }^{\mathrm{I}} \alpha$ and ${ }^{\mathrm{II}} \alpha$, and three of $\beta$ type, ${ }^{\mathrm{I}} \beta,{ }^{\mathrm{II}} \beta$, and ${ }^{\mathrm{III}} \beta$ (Travnicek et al., 1971; Garrick et al., 1975). The polymorphism in rat hemoglobins probably involves the ${ }^{\mathrm{III}} \beta$ chain as described by Garrick et al. (1975) which comprises about $20 \%$ of the $\beta$ chains. Components $\mathrm{c}$ and d (Fig. 1) of type A rats probably share ${ }^{\text {III }} \beta$, but have differing $\alpha$ chains, based on the work of Garrick et al. (1975). These workers used cellulose acetate rather than starch gel, but the separations are similar. In type B animals, we hypothesize that the III $\beta$ chain is altered from that of type A animals, changing the $c$ and $d$ components of type A to the $d$ and e positions, respectively. This view is supported by the observation that the faster-migrating of these two components stains somewhat more intensely in both A and B types (Fig. 1). Further evidence that the $d$ band of hemoglobin A and hemoglobin B type animals is not identical is the observation that migration of this band in A type averages $10 \%$ less than in $\mathrm{B}$ type. This is difficult to demonstrate clearly in a 
single picture as in Fig. 1, but it is a consistent finding. This is further evidence that these two cathodal components are both involved in the polymorphism through a shared polypeptide chain, since both shift position between the $\mathrm{A}$ and $B$ phenotypes.

Noble and Brewer (1977) have previously described a locus responsible for variation in DPG concentration in the blood of Long-Evans hooded rats. Two lines were generated by selection, one homozygous for the high-DPG gene (genotype $D D$ ) and the other homozygous for the low-DPG gene (genotype $d d$ ). The difference in DPG concentration in the blood of high-DPG and low-DPG rats causes a difference in the oxygen affinities of the bloods of the two types. High-DPG rats have blood with lower oxygen affinity; on the average, for high-DPG rats the p50 (the partial pressure of oxygen required for half-saturation of the blood with oxygen) is about $6 \mathrm{~mm} \mathrm{Hg}$ higher than the p50 for low-DPG rats (Brewer et al., 1972).

In this article, we have shown that the high-DPG line was homozygous for the $b$ hemoglobin allele and that the low-DPG line was homozygous for $a$. Our $F_{2}$ intercross study of Table II shows conclusively that this association of the $D$ allele with $b$ and of $D$ with $a$ is a genetic one, i.e., hemoglobin A progeny predominantly have low DPG levels, hemoglobin B progeny predominantly have high DPG levels. Of the $70 \mathrm{~F}_{2}$ animals, only one gave good evidence for a recombination event having occurred between the hemoglobin and DPG loci. In addition to the segregation data resulting from the mating of this animal reported in the Results section, the hypothesis of recombination is further supported by studies of glycolytic intermediates. The $\mathrm{F}_{2}$ putative recombinant and her two putative $D d$ a a type offspring have red cell glycolytic intermediate patterns of relatively low glucose-6-phosphate and fructose-6-phosphate levels, and relatively high fructose diphosphate and succeeding intermediates in the glycolytic pathway compared to levels of these intermediates in $d d$ animals. This pattern, which suggests relatively greater phosphofructokinase activity in the cell, is typical of high-DPG $(D D$ or $D d)$ animals when compared to low-DPG $(d d)$ animals (Noble and Brewer, 1972). The $F_{2}$ data of Table II, however, also suggest the possible existence of at least minor modifiers of DPG concentration over and above the alleles at the $D$ locus, so that any interpretation of the occurrence of a recombination event must be cautious.

The association of the $b$ hemoglobin allele with the $D$ allele for DPG level, and that of $a$ with $d$, also occurs in the random-bred Long-Evans hooded rat population of Simonsen Laboratories (from which our high-DPG and low-DPG lines were derived), as shown in Table III. The A hemoglobin animals had low DPG levels, and the B hemoglobin type animals predominantly had high DPG levels.

The genetic mechanism of the association between these hemoglobin and DPG types in Long-Evans hooded rats includes two alternative hypotheses. 
One is close genetic linkage between the hemoglobin locus and the DPG locus, with severe linkage disequilibrium such that hemoglobin $b$ and DPG $D$ alleles are usually coupled and hemoglobin $a$ and DPG $d$ alleles are usually coupled. The second possibility is that only one locus is involved, causing both phenotypes.

First, we will briefly review the evidence favoring each of these hypotheses. We can be reasonably certain that the hemoglobin locus exists as an entity, because of the electrophoretic evidence of two codominant genes. At present, we do not have definitive evidence of a separate DPG-determining locus. The only additional biochemical information we have on this point is that the glycolytic intermediate patterns are different in the two rat lines (Noble and Brewer, 1972). The glycolytic intermediate patterns are such that they suggest a more active phosphofructokinase (PFK) enzyme in the high-DPG line than in the low-DPG line. These data are compatible with different structural alleles for PFK in the two lines, but certainly do not prove this point. Further biochemical characterization of PFK in these lines has not yet been carried out.

In addition to biochemical studies which could produce evidence of a separate structural locus determining DPG phenotypes, genetic studies showing recombination can also provide evidence for the existence of two loci. In the present article, one animal of $70 \mathrm{~F}_{2}$ test progeny appears to be a recombinant. While the evidence already discussed for recombination in this animal is good, it is not absolute, because we have no definitive way of establishing that the elevated DPG in this $a a$ animal and its progeny is due to the presence of the $D$ allele under consideration. Since these animals are not highly inbred, coincidental occurrence of other DPG-influencing alleles, perhaps made more potent in a particular genetic background, is always a possibility. In extensive studies of DPG levels in these rats over several years we have found no evidence for the existence of a major gene affecting DPG levels other than the one we have been discussing, but it must be admitted that the existence of another major modifier, particularly if its influence depends on other factors, cannot be excluded.

The studies in the inbred rat lines (Table IV) also are against the onelocus hypothesis, in view of the lack of a strong association between hemoglobin and DPG phenotypes. However, these data are also not definitive on this point, because we cannot be certain that the DPG phenotypes are due to variation in the $D$ locus we are dealing with in the hooded animals.

The one-locus hypothesis assumes that the hemoglobin variation causes the variation in DPG levels. The biochemical mechanism of this might be differences in binding of DPG or other glycolytic factors by the two types of hemoglobin. Mammalian hemoglobins do, of course, bind DPG and other glycolytic intermediates. So far, no studies of differential binding of the two types of hemoglobin in these rats have been carried out. 
The two-locus hypothesis seems more plausible to us, in view of the one probable recombinant animal and other considerations described earlier, but the existence of marked linkage disequilibrium needs explanation. The LongEvans hooded population of Simonsen Laboratories has been in existence for 60 years and approximately 200 generations (personal communication). At a recombination rate as low as 0.01 , in the absence of selection, one-half of an initial disequilibrium will be lost in about 69 generations (Crow and Kimura, 1970). Even at a recombination rate of 0.005 , one-half disequilibrium would be lost in 138 generations. The recombination rate would have to be of the order of 0.001 to be compatible with the observed disequilibrium, and the observation of one probable recombinant in $70 \mathrm{~F}_{2}$ progeny suggests that the recombination rate is higher than this.

Disequilibrium could also be explained by recombination suppression or by selection against certain linkage types. In the former case, the actual recombination rate would have to be as low as 0.001 , and the observation of one probably recombinant out of $70 \mathrm{~F}_{2}$ progeny also argues against this mechanism. Selection against recombinants remains a possibility which we are in the process of testing in the descendants of the putative recombinant.

Assuming that a favored relationship between $D$ and $b$, and $d$ and $a$, has been maintained in the Long-Evans hooded population by selection against recombinants or other genetic mechanism, the question of the possible physiological advantage of these relationships must be asked. It may be of importance that the hemoglobin components involved, while comprising only $20 \%$ of adult hemoglobins, are the predominant hemoglobins synthesized in the anemic period after bleeding (Travnicek et al., 1967; Travnicek and Sulc, 1967; Travnickova and Sulc, 1970; Sulc et al., 1976). These components are also predominant during fetal and early neonatal life (Brdicka, 1966; Travnicek et al., 1966; Travnicek and Sulc, 1967; Travnickova and Sulc, 1970). It may be that in hypoxia and in fetal life these are the most important hemoglobin components and that at least in the Long-Evans hooded strain a very special relationship with DPG levels exists.

Regardless of the ultimate explanation of the association between hemoglobin and DPG types, the existence of this association is interesting. Hemoglobin, a structural protein for oxygen transport, and DPG, a three-carbon metabolite, are functionally related. The genetic and physiological mechanisms producing an association of phenotypes involving these very different molecules are sure to be of interest.

\section{REFERENCES}

Benesch, R., and Benesch, R. E. (1967). The effect of organic phosphates from the human erythrocyte on the allosteric properties of hemoglobin. Biochem. Biophys. Res. Commun. 26:162. 
Brdicka, R. (1966). Zur Ontogenese der Rattenhamoglobine. Acta Biol. Med. Ger. 16:617.

Brdicka, R. (1967). On the ontogenesis and genetics of rat hemoglobins. Thesis, 1967.

Brewer, G. J. (1974). Red cell metabolism and function. In Surgenor, D. M. (ed.), The Red Blood Cell, Vol. 1, Academic Press, New York, Chap. 11.

Brewer, G. J., and Eaton, J. W. (1971). Erythrocyte metabolism: Interaction with oxygen transport. Science 171:1205.

Brewer, G. J., Oelshlegel, F. J., Jr., and Eaton, J. W. (1972), Oxygen affinity of hemoglobin and red cell acid base status. In Rorth, M., and Astrup, P. (eds.), Alfred Benzon Symposium IV, Academic Press, New York, pp. 539-551.

Chanutin, A., and Curnish, R. R. (1967). Effect of organic and inorganic phosphates on the oxygen equilibrium of human erythrocytes. Arch. Biochem. 121:96.

Crow, J. F., and Kimura, M. (1970). An Introduction to Population Genetics Theory, Harper and Row, New York.

French, E. A., and Roberts, K. B. (1965). The multiple haemoglobins of the rat. Proc. Physiol. Soc. 22:16P.

French, E. A., Roberts, K. B., and Searle, A. G. (1971). Linkage between a hemoglobin locus and albinism in the Norway rat. Biochem. Genet. 5:397.

Garrick, L., Sharma, V. S., McDonald, M. J., and Ranney, H. M. (1975). Rat haemoglobin heterogeneity. Biochem. J. 149:245.

Keitt, A. S. (1971). Reduced nicotinamide adenine dinucleotide-linked analysis of 2,3-diphosphoglyceric acid: Spectrophotometric and fluorometric procedures. J. Lab. Clin. Med. $77: 470$.

Marinkovic, D., Martinovic, J., and Kanazir, D. (1967). Electrophoretic haemoglobin patterns in one random bred and two inbred strains of laboratory rats. Nature 1:819.

Martinovic, J., Marinkovic, D. V., Kanazir, D. T., and Martinovitch, P. N. (1970). Inheritable differences in the electrophoretic pattern of hemoglobin revealed in a local random-bred colony of albino rats. Blood 35:447.

Noble, N. A., and Brewer, G. J. (1972). Studies of the metabolic basis of the ATP-DPG differences in genetically selected High and Low ATP-DPG rat strains. In Brewer, G. J. (ed.), Hemoglobin and Red Cell Structure and Function, Plenum, New York, pp. 155-164.

Noble, N., and Brewer, G. J. (1977). Identification of a major locus contributing to erythrocyte 2,3-diphosphoglycerate variability in hooded (Long-Evans) rats. Genetics 85:4.

Smithies, O. (1965). Proc. 10th Congr. Int. Soc. Blood Transf., Stockholm, 1964, p. 1175.

Sulc, K., Travnicek, T., Neuwirt, J., and Radikovska, E. (1976). Haemoglobin types in peripheral blood and bone marrow cells in rats after a single blood loss. Physiol. Bohemoslov. 25:345.

Travnicek, T., and Sulc, K. (1967). A comparison of the separation of rat haemoglobin on starch-gel electrophoresis and on CM-Sephadex. Physiol. Bohemoslov. 16:330.

Travnicek, T., Travnickova, E., and Sulc, K. (1966). Changes in Hb fractions separated on CM-Sephadex in normal newborn rats and in newborn rats after repeated blood losses. Physiol. Bohemoslov. 15:75.

Travnicek, T., Sulc, K., and Travnickova, E. (1967). Changes in haemoglobin separation on CM-Sephadex in adult rats after blood loss. Physiol. Bohemoslov. 16:160.

Travnicek, T., Borova, J., and Sulc, K. (1971). Subunit composition of polymorphic rat haemoglobins. Physiol. Bohemoslov. 20:27.

Travnickova, E., and Sulc, K. (1970). Effect of repeated blood loss on haemoglobin synthesis in young rats. Physiol. Bohemoslov. 19:243. 